\title{
Sikap dan Dukungan Suami dengan Pemakaian Metode Kontrasepsi Jangka Panjang (MKJP) Aseptor KB Baru
}

\author{
Elis Yuliarti ${ }^{1 *}$, Komalasari $^{2}$, Fitriana $^{3}$, Septika Yani Veronica ${ }^{4}$ \\ ${ }^{1,2,4}$ Departemen Kebidanan, Universitas Aisyah Pringsewu \\ ${ }^{3}$ Dinas Kesehatan Kabupaten Pringsewu, Lampung, Indonesia
}

Email: elisyuliarti201@gmail.com

\begin{tabular}{|c|c|}
\hline ARTICLE INFO & ABSTRACT \\
\hline $\begin{array}{l}\text { *) corresponding author } \\
\text { Elis Yuliarti } \\
\text { Mahasiswa Prodi Kebidanan, Fakultas } \\
\text { Kesehatan, Universitas Aisyah Pringsewu, } \\
\text { Lampung, Indonesia }\end{array}$ & $\begin{array}{l}\text { The world population continues to grow and has reached } 7.2 \text { billion in } \\
2013 \text {, as well as in Indonesia.LTCM The research objective was to } \\
\text { determine the Relationship Between Husband's Attitude and Support of } \\
\text { Using LTCM on Primary Birth Control Acceptor at Community Health } \\
\text { Center Tanjung Agung Baturaja in 2020. The type is quantitative } \\
\text { analytical research design with cross-sectional approach. The } \\
\text { population wereall primary birth control acceptorin the working area } \\
\text { of Community Health Center TanjungAgungBaturaja, from January up } \\
\text { to December } 2019 \text { as much as 510. In taking the sample is using cluster } \\
\text { sampling. The data analysis uses the chi square test. The results of } \\
\text { analysis and processingdata shows that there is a relationship between } \\
\text { attitude and the use of LTCM on Primary Birth Control Acceptorwith p- } \\
\text { value 0.003 (less than 0.05) and there is no relationship between } \\
\text { husband's support and the use of LTCM on Primary Birth Control } \\
\text { Acceptorwith p-value 0.964 (more than 0.05). It is expected that the } \\
\text { results of this research increase the knowledge and understanding of } \\
\text { reproductive-age mothers about contraceptive methods, especially in } \\
\text { long-term contraception so that they are more stable in choosing the } \\
\text { LTCM. }\end{array}$ \\
\hline
\end{tabular}

This is an open access article under the CC-BY-SA license.

\section{PENDAHULUAN}

Jumlah penduduk dunia terus tumbuh dan telah mencapai 7,2 milyar pada tahun 2013, Hasil sensus penduduk 2015 menempatkan posisi Indonesia di urutan keempat setelah China, India, Amerika Serikat (Budiarti, et al, 2017). Menurut data hasil riset kesehatan dasar (Riskesdas) tahun 2018 proporsi pengunaan KB moderen yang digunakan setelah melahirkan anak terakhir pada perempuan umur 10-54 tahun di Indonesia tercatat sebanyak 78,568 pengguna. 
Metode kontrasepsi jangka panjang (MKJP) merupakan metode kontrasepsi yang mempunyai tingkat efektifitas tinggi. Metode ini antara lain implan, intra uterine device (IUD), metodeo perasi wanita (MOW) atau tubektomi dan metode operasi pria (MOP) atauvasektomi. Kecenderungan pasangan usia subur (PUS) untuk memilih metode non MKJP masih tinggi meskipun dengan potensi kegagalan kontrasepsi yang besar, baik di karenakan penggunaan yang salah ataupun pemakaian yang tidak teratur dan efek samping yang membuat tidak nyaman.

Belum meratanya promosi dan KIE yang menjangkau seluruh lapisan masyarakat sehingga mempengaruhi pengetahuan dan sikap peserta Akseptor, anggapan miring dari masyarakat tentang kontrasepsi jangka panjang, ketakutan dari Akseptor sendiri mengenai proses penggunaan KB MKJP dan meningkatnya kampanye penggunaan kontrasepsi hormonal (pil dan suntik) oleh swasta (produkan dalan) (Dinas P2KBP3A, 2017).

Berdasarkan studi pendahuluan yang dilakukan di Puskesmas Tanjung Agung Baturaja Kabupaten Oku didapatkan data jumlah peserta KB aktif yang menggunakan kontrasepsi MKJP di Puskesmas Tanjung Agung Baturaja tahun 2019 sebanyak 692 dari 5.013 peserta KB, dan jumlah peserta KB baru yang menggunakan kontrasepsi MKJP sebanyak 14 orang dari 510 peserta KB dengan pembagian implant sebanyak 13 dan IUD sebanyak 1 orang. Hal tersebut menunjukkan bahwa peserta KB kontrasepsi MKJP di Puskesmas Tanjung Agung merupakan yang paling rendah diantara kontrasepsi yang lainnya. Selain itu, Penguna kontrasepsi jangka panjang seperti implant dan IUD masih kurang penggunanya dan masih di dominasiol masih kurang penggunanya dan masih didominasi oleh metode kontrasepsi jangka pendek seperti pil dan suntik.

\section{METODE}

Penelitian ini merupakan penelitian kuantitatif dengan pendekatan cross sectional. Variabel bebas dalam penelitian ini adalah sikap dan dukungan keluarga. Data yang digunakan dalam penelitian ini adalah data primer yang artinya data diperoleh dari responden langsung kepada akseptor KB baru di Wilayah Kerja Puskesmas Tanjung Agung. Populasi pada penelitian ini seluruh akseptor KB baru di wilayah kerja Puskesmas Tanjung Agung Baturaja dari data bulan JanuariDesember tahun 2019 sebanyak 510.

Cara pengumpulan data pada penelitian ini dengan metode pengisian lembar kuesioner oleh responden dengan cara peneliti melakukan wawancara kepada askseptor KB baru di Wilayah Kerja Puskesmas Tanjung Agung yang terbagi kedalam 12 desa setiap masing-masing desa di ambil sampel. Alat pengumpulan data yang digunakan peneliti adalah kuesioner atau angket yang disesuaikan dengan dengan tujuan penelitian dan mengacu kepada konsep dan teori yang telah dibuat. Pertanyaan terdiri dari 4 bagian yaitu data demografi, dukungan suami, sikap ibu, dan kontrasepsi MKJP. Pengolahan data dalam penelitian ini menggunakan uji validitas dan reliabilitas.

\section{HASIL DAN PEMBAHASAN}

Tabel 1

Distribusi frekuensi Sikap, dukungan suami dan pemakaian MKJP pada Aseptor KB Baru (N=84)

\begin{tabular}{|c|c|c|}
\hline Variabel & Frekuensi & Persentase (\%) \\
\hline \multicolumn{3}{|l|}{ Sikap } \\
\hline Negatif & 44 & 52.4 \\
\hline Positif & 40 & 47.6 \\
\hline \multicolumn{3}{|l|}{ Dukungan suami } \\
\hline Tidak Mendukung & 39 & 46.4 \\
\hline Mendukung & 45 & 53.6 \\
\hline \multicolumn{3}{|l|}{ Pemakaian MKJP } \\
\hline Non MKJP & 72 & 85.7 \\
\hline MKJP & 12 & 14.3 \\
\hline
\end{tabular}


Dari 84 responden, $44(52.4 \%)$ dengan sikap negatif dan $40(47.6 \%)$ sikap positif sebesar 40 (47,6\%). Dari 84 responden, 39 (46.4\%) suami tidak dan 45 (53.6\%) suami mendukung. yang relevan, mutakhir dan primer. Dari 84 responden, $72(85.7 \%)$ responden non MKJP dan $12(14.3 \%)$ responden memakai.

Tabel 2

Hubungan sikap dengan pemakaian $\operatorname{MKJP}(\mathbf{N}=84)$

\begin{tabular}{|c|c|c|c|c|c|c|c|c|}
\hline \multirow{3}{*}{ Sikap } & \multicolumn{6}{|c|}{ Pemakaian MKJP } & \multirow{3}{*}{ p-value } & \multirow{3}{*}{ OR $(95 \%$ CI $)$} \\
\hline & \multicolumn{2}{|c|}{ Non MKJP } & \multicolumn{2}{|c|}{ MKJP } & \multicolumn{2}{|c|}{ Total } & & \\
\hline & $\mathbf{F}$ & $\%$ & $\mathbf{F}$ & $\%$ & $\mathbf{F}$ & $\%$ & & \\
\hline Negatif & 43 & 97.7 & 1 & 2.3 & 44 & 100 & \multirow{2}{*}{0.003} & \multirow{2}{*}{$\begin{array}{c}16.310 \\
(133.272-1.996)\end{array}$} \\
\hline Positif & 29 & 72.5 & 11 & 27.5 & 40 & 100 & & \\
\hline
\end{tabular}

Responden non MKJP dengan sikap negatif sebesar 43 (97.7\%) dan positif sebesar 29 (72.5\%), yang menggunakan MKJP dengan Responden non MKJP dengan sikap negatif sebesar 43 (97.7\%) dan positif sebesar 29 (72.5\%), yang menggunakan MKJP dengan sikap negatif sebesar 1 (2.3\%) dan dengan sikap positif sebesar 11(27.5\%).

Tabel 3

Hubungan Dukungan Suami dengan pemakaian MKJP (N=84)

\begin{tabular}{|c|c|c|c|c|c|c|c|c|}
\hline \multirow{3}{*}{ Dukungan Suami } & \multicolumn{6}{|c|}{ Pemakaian MKJP } & \multirow{3}{*}{ p-value } & \multirow{3}{*}{ OR $(95 \%$ CI $)$} \\
\hline & \multicolumn{2}{|c|}{ Non MKJP } & \multicolumn{2}{|c|}{ MKJP } & \multicolumn{2}{|c|}{ Total } & & \\
\hline & $\mathbf{F}$ & $\%$ & $\mathbf{F}$ & $\%$ & $\mathbf{F}$ & $\%$ & & \\
\hline Tidak Mendukung & 34 & 87.2 & 5 & 12.8 & 39 & 100 & \multirow{2}{*}{0.964} & \multirow{2}{*}{$\begin{array}{c}1.253 \\
(4.317-0.363)\end{array}$} \\
\hline Mendukung & 38 & 84.2 & 7 & 15.6 & 45 & 100 & & \\
\hline
\end{tabular}

Suami tidak mendukung sebesar 34 (87.2\%) dan yang mendukung sebesar 38 (84.2\%), yang menggunakan MKJP dengan suami tidak mendukung sebesar 5 (12.8\%) dan dengan suami yang mendukung sebesar 7 (15.6\%). Didapatkan Pvalue 0,964 (>0.05) yang berarti tidak ada hubungan dukungan suami dengan pemakaian Metode Kontrasepsi Jangka Panjang (MKJP) Aseptor KB Baru.

\section{Keterbatasan Penelitian}

Populasi dalam penelitian adalah seluruh akseptor KB baru di wilayah kerja Puskesmas Tanjung Agung Baturaja yaitu dari data bulan Januari-Desember tahun 2019 sebanyak 510. Teknik sampling yang digunakan dalam penelitian ini adalah menggunakan metode cluster sampling. Adapun kriteria sampel dalam penelitian ini adalah sebagai berikut a) ibu yang mengikuti program KB, b) tinggal diwilayah Puskesamas Tanjung Agung, c) bersedia menjadi responden, d) tidak mengalami ganguan komuniksasi dand dapat membaca dan menulis.

Instrument penelitian adalah alat atau fasilitas yang digunakan oleh peneliti untuk mengumpulkan data, Alat pengumpulan data yang digunakan peneliti adalah kuesioner atau angket yang disesuaikan dengan dengan tujuan penelitian dan mengacu kepada konsep dan teori yang telah dibuat

\section{Hubungan Sikap dengan Pemakaian Metode Kontrasepsi Jangka Panjang}

Berdasarkan hasil penelitian dapat dijelaskan bahwa dari 84 responden, 44 (52.4\%) dengan sikap negatif dan 40 (47.6\%) dengan sikap positif dalam pemakaian Metode Kontrasepsi Jangka Panjang (MKJP). Dapat disimpulkan bahwa sebagian besar responden dengan sikap negatif dalam pemakaian Metode Kontrasepsi Jangka Panjang (MKJP). 
Berdasarkan hasil pengolahan data didapatkan Pvalue 0,003 $(<0.05)$ yang berarti tedapat hubungan sikap dengan pemakaian Metode Kontrasepsi Jangka Panjang (MKJP)Aseptor KB Baru

Dari hasil penelitian ini dapat diasumsikan bahwa responden dengan sikap negatif pernah ada keinginan untuk memilih Metode Kontrasepsi Jangka Panjang (MKJP), namun ada perasaan ragu mengenai lamanya penggunaan metode tersebut serta kurangnya pemahan mereka mengenai Metode Kontrasepsi Jangka Panjang (MKJP).

\section{Hubungan Dukungan Suami dengan Pemakaian MKJP}

Berdasarkan hasil penelitian dapat dijelaskan bahwa dari 84 responden, 39 (46.4\%) suami tidak mendukung dalam penggunaan Metode Kontrasepsi Jangka Panjang (MKJP) dan 45 (53.6\%) suami mendukung dalam penggunaan Metode Kontrasepsi Jangka Panjang (MKJP). Dapat disimpulkan bahwa sebagian besar suami tidak mendukung dalam penggunaan Metode Kontrasepsi Jangka Panjang (MKJP).

Hasil pengolahan data didapatkan Didapatkan Pvalue 0,964 (>0.05) yang berarti tidak ada hubungan dukungan suami dengan pemakaian Metode Kontrasepsi Jangka Panjang (MKJP)Aseptor KB Baru.

Dari hasil penelitian ini dapat diasumsikan bahwa suami yang tidak mendukung karena kurangnya pengetahuan suami tentang kontrasepsi sehingga suami lebih memilih mengikuti saran dan kemauan istrinya. Suami responden tidak mendukung istrinya untuk menggunakan alat kontrasepsi (Veronica, S., Safitri, R., \& Rohani, S. 2019). Hal tersebut dikarenakan tidak adanya komunikasi antar suami istri dalam menentukan pilihan menggunakan kontrasepsi jangka panjang dan suami tidak ingin ikut andil dalam pemilihan alat kontrasepsi (Ningsih., Firdawati., \& Satria, 2019).

\section{SIMPULAN DAN SARAN}

Program keluarga berencana untuk memenuhi perintah masyarakat akan pelayanan keluarga berencana dan kesehatan reproduksi yang berkualitas. Tidak ada satupun metode kontrasepsi yang aman dan efektif bagi semua klien karena masing-masing mempunyai kesesuaian dan kecocokan individual bagi setiap klien (BKKBN, 2011). Di Puskesmas Tanjung Agung Baturaja tahun 2020 terdapat Distribusi frekuensi Sikap suami dalam pemakaian Metode Kontrasepsi Jangka Panjang (MKJP) Aseptor KB baru diperoleh 44 (52.4\%) dengan sikap negatif dan 40 (47.6\%) dengan sikap positif dalam pemakaian Metode Kontrasepsi Jangka Panjang (MKJP). Distribusi frekuensi dukungan suami diperoleh 39 (46.4\%) suami tidak mendukung dalam penggunaan Metode Kontrasepsi Jangka Panjang (MKJP) dan 45 (53.6\%) suami mendukung dalam penggunaan Metode Kontrasepsi Jangka Panjang (MKJP). Distribusi frekuensi pemakaian Metode Kontrasepsi Jangka Panjang (MKJP) Aseptor KB Baru diperoleh 72 (85.7\%) responden non MKJP dan 12 (14.3\%) responden memakai MKJP.Tedapat hubungan sikap dengan pemakaian Metode Kontrasepsi Jangka Panjang (MKJP) Aseptor KB Barudiperoleh p-value 0,003 $(<0.05)$ dan Tidak tedapat hubungan dukungan suami dengan pemakaian Metode Kontrasepsi Jangka Panjang (MKJP) Aseptor KB Baru diperoleh p-value 0,964 (>0.05).Berdasarkan hasil tersebut menunjukkan bahwa hubungan yang signifikan antara dukungan suami dengan pemilihan metode kontrasepsi. Artinya dukungan suami mempengaruhi pemilihan metode kontrasepsi di Puskesmas Tanjung Agung Baturaja tahun 2020.

Penelitian ini dapat menambah pengetahuan dan pemahaman ibu usia reproduksi tentang metode kontrasepsi khususnya pada kontrasepsi jangka panjang sehingga lebih memantapkan mereka dalam memilih Metode Kontrasepsi Jangka Panjang (MKJP).menjadi masukan dalam rangka peningkatan pencapaian program ber-KB melalui persetujuan atau dukungan dari pasangannya dan sebagai pemberian konseling yang merupakan aspek penting dalam pelayanan keluarga berencana dan kesehatan reproduksi. 


\section{DAFTAR PUSTAKA}

BKKBN. (2011). Pedoman Pelaksanaan Pelayanan KB Metode Kontrasepsi Jangka Panjang. Jakarta:BKKBN.

Budiarti, Indah, etal. (2017). Determinan Penggunaan Metode Kontrasepsi Jangka Panjang (MKJP) Pada Akseptor KB. Jurnal Kesehatan vol 8 no.2.

Dinas P2KBP3A. (2017). Laporan Bulanan Capaian KB Tahun 2015-201

Ningsih, D., Firdawati, F., \& Satria, P. (2019). Awarding Support Becomes a Dominant Factor in the Election of Family Planning in the Long-Term Contraception Method in Kampung KB. Jurnal Aisyah : Jurnal Ilmu Kesehatan, 4(1), 73-81. doi:https://doi.org/10.30604/jika.v4i1.185

Veronica, S., Safitri, R., \& Rohani, S. (2019). Faktor-Faktor yang Berhubungan dengan Pemakaian KB IUD PADA Wanita Usia Subur. Wellness And Healthy Magazine, 1(2), 223-230. Retrieved from https://wellness.journalpress.id/wellness/article/view/v1i228wh 